\title{
OS SISTEMAS COMERCIAIS URBANOS EM TEMPOS DE TURBULÊNCIA: VULNERABILIDADES E NÍVEIS DE RESILIÊNCIA
}

\author{
Herculano Cachinho ${ }^{1}$
}

Teresa Barata Salgueiro ${ }^{1}$

\begin{abstract}
RESUMO - A mudança sempre moldou os sistemas comerciais, mas nas últimas décadas a aceleração do seu ritmo fez com que, em muitas cidades, estes entrassem em desequilíbrio e deixassem de responder com eficiência às necessidades de abastecimento dos diferentes grupos de consumidores. Partindo do pressuposto que o comércio é um elemento vital à sustentabilidade urbana e que o planeamento pode contribuir para o seu desenvolvimento mais eficiente, neste artigo apresenta-se o quadro conceptual e metodológico do Projeto REPLACIS para avaliar as vulnerabilidades e os níveis de resiliência dos sistemas comerciais urbanos. Assim, o artigo comporta duas partes. Na primeira faz-se uma análise das principais mudanças sofridas pelo comércio na cidade nas últimas décadas e discute-se o conceito de resiliência tendo em vista a sua aplicação aos sistemas comerciais. Na segunda apresenta-se o quadro conceptual e metodológico usado no projeto. Encerra-se com umas breves notas finais sobre as potencialidades e limitações do modelo, enquanto ferramenta para a avaliação da vitalidade dos sistemas comerciais na perspetiva da sustentabilidade e da resiliência urbanas.
\end{abstract}

Palavras-chave: REPLACIS; Sistema comercial; Resiliência; Sustentabilidade urbana.

ABSTRACT - URBAN RETAIL SYSTEMS IN TIMES OF TURBULENCE: LEVELS OF VULNERABILITY AND RESILIENCE. Change has always been a significant attribute of urban retail systems. However, in recent decades, not only has the pace of these changes been dramatically intensified but also their scope has broadened significantly, engendering large imbalances in the structure and spatial organization of urban retail systems. Often, these changes not only challenge the vitality and the economic viability of the retail systems but also jeopardize the sustainability of cities. Departing from the assumption that retailing as a key element of urban sustainability, and that planning policies can contribute to its efficient development, 
this article focuses on the presentation of the conceptual and methodological framework used in the REPLACIS Project to assess the vulnerabilities and the resilience levels of urban retail systems. Thus, the paper comprises two parts. The first is focused on the major changes that urban retailing has undergone and on the discussion of the concept of resilience applied to retail systems. The second presents the analytical dimensions of the conceptual and methodological framework. The article ends with a brief reflection on the strengths and limitations of the model as a tool for the assessment of the vitality and viability of retail systems from the perspective of urban resilience.

Keywords: REPLACIS; Urban retail system; Resilience; Urban sustainability.

RESUME - LES SYSTÈMES COMMERCIAUX URBAINS EN PÉRIODES DE TURBULENCE : vUlNÉRABILITÉS ET NIVEAUX DE RÉSILIENCE. Tout changement affecte les systèmes commerciaux, mais l'accélération de leur rythme au cours des dernières décennies a fait que ces systèmes entrent en déséquilibre e cessent de répondre efficacement aux nécessités d'approvisionnement des divers groupes de consommateurs. En admettant que le commerce soit un élément vital de la durabilité urbaine et que la planification puisse contribuer à un développement plus efficace, on présente le cadre conceptuel et méthodologique utilisé par le Projet REPLACIS pour évaluer les vulnérabilités et les niveaux de résilience des systèmes commerciaux urbains. Dans la première partie de l'article, on analyse les principaux changements ayant affecté le commerce urbain au cours des dernières décennies et on discute l'application possible du concept de résilience aux systèmes commerciaux. Dans la seconde partie, on présente le cadre conceptuel et méthodologique utilisé dans ce Projet. De brèves notes finales indiquent les potentialités et les limites du modèle utilisé pour évaluer la vitalité des systèmes commerciaux, dans une perspective de durabilité et de résilience urbaines.

Mots clés: REPLACIS; Système commercial; Résilience; Durabilité urbaine.

\section{INTRODUÇÃO}

A mudança sempre moldou o comércio urbano, sendo os comerciantes e os consumidores os seus arquitetos por excelência (Borchert, 1998). Os comerciantes, porque inseridos em ambientes exigentes e competitivos, para expandirem os negócios necessitam de inovar nas estratégias de gestão, lançar no mercado produtos inovadores e criar novas lojas e ambientes de consumo. Por sua vez, os consumidores, movidos por motivações pessoais ou engendradas pela sociedade estão continuamente a renovar as suas necessidades e desejos, a alterar os comportamentos e estilos de vida, com reflexos nas práticas de consumo.

Embora a mudança seja intrínseca aos sistemas comerciais, a verdade é que nas últimas décadas esta acelerou de tal forma o seu ritmo, que, em muitas cidades, estes se tornaram fonte de muitos conflitos. Frequentemente, estas mudanças, além de abalarem a viabilidade económica de muitas lojas e áreas comerciais, acabaram também por marginalizar os consumidores com menor mobilidade e poder de compra e, por essa via, colocar em causa o desenvolvimento sustentável das cidades. O declínio dos pequenos comer- 
ciantes em detrimento das cadeias de distribuição, o enfraquecimento do centro das cidades face ao crescente protagonismo dos subúrbios, o empobrecimento do comércio de bairro em contraste com a difusão das grandes superfícies orientadas para os consumidores motorizados, ou ainda a desvalorização das lojas utilitárias em relação aos espaços ancorados nas economias do fascínio e da atenção, são hoje uma característica partilhada pelas cidades de diferentes contextos culturais.

Sendo o comércio crucial ao funcionamento da cidade, o projeto Retail Planning for Cities Sustainability (REPLACIS) faz depender a sustentabilidade urbana da preservação de sistemas comerciais diversificados, com capacidade para responder às necessidades dos diferentes grupos de consumidores. As tendências da distribuição têm mostrado que os conceitos comerciais e os centros de comércio são dotados de diferentes níveis de resiliência, que podem ser robustecidos através das políticas e do planeamento. Partindo destes princípios, o projeto tinha como missão contribuir para a compreensão das mudanças que afeiçoam o comércio na cidade e conceber um quadro analítico que suporte as ações em prol da preservação do equilíbrio dos sistemas comerciais e da sustentabilidade urbana.

Este artigo tem como finalidade analisar de forma crítica o quadro conceptual e metodológico do projeto REPLACIS ${ }^{\mathrm{i}}$. Assim, depois de se apresentarem as grandes mudanças sofridas pelo comércio em meio urbano, discute-se o conceito de resiliência e o interesse da sua aplicação aos sistemas comerciais. Num segundo momento, apresentam-se as dimensões analíticas do quadro conceptual e metodológico. Por último, faz-se uma reflexão sobre as potencialidades e limitações do modelo, e o seu interesse para a avaliação da vitalidade dos sistemas comerciais na perspetiva da sustentabilidade e da resiliência urbanas.

\section{AS DINÂMICAS DOS SISTEMAS COMERCIAIS}

O comércio é, por excelência, uma atividade urbana e, apesar das potencialidades do comércio eletrónico, dificilmente o deixará de ser no futuro. Os requisitos de centralidade e acessibilidade a par das economias de aglomeração explicam, em grande medida, esta imbricação. De facto, quando os consumidores escasseiam, como acontece nas aldeias, o comércio desaparece ou limita a sua presença às funções mais básicas. As restantes, que oferecem bens e serviços de aquisição ocasional, são disponibilizadas nestes lugares pelos vendedores ambulantes, ou pelas feiras, de periodicidade e área de influência variável.

As relações entre o comércio e a cidade perdem-se no tempo. Se nem todas as cidades são "filhas do comércio», como sugeriu Pirenne (1969), a verdade é que em nenhuma civilização a vida urbana floresceu sem a presença das trocas. $O$ comércio faz parte da razão de ser da cidade. Viabiliza a sua existência, explica a sua organização interna e justifica muita da animação que nesta acontece. Através do comércio as pessoas satisfazem necessidades, veicula-se informação, difundem-se inovações, criam-se laços de sociabili- 
dade, a vida acontece. Em suma, no comércio reside o embrião da vida urbana naquilo que esta pressupõe de interação, de troca em sentido lato e de produção de inovação (Barata-Salgueiro, 1996).

No entanto, as relações que o comércio estabelece na atualidade com a cidade são bem diferentes das vividas noutros tempos. Alguns autores consideram mesmo que se assistiu a uma verdadeira revolução comercial (Bromley \& Thomas, 1993; Lichtenstein, 2009; Moati, 2011). Independentemente das diferenças que se possam observar nos distintos contextos geográficos, os impactos desta "revolução" são hoje visíveis em inúmeros domínios, desde a composição económica do setor à sua organização espacial, passando pelo significado das lojas ou a forma como os indivíduos experienciam e se relacionam com a cidade mediante os atos da compra e do abastecimento.

Em primeiro lugar, num curto período de tempo, o comércio passou de um setor relativamente estático para um dos mais dinâmicos da economia urbana. E esta mudança fez toda a diferença. A diversidade de bens e serviços que hoje se encontram no mercado e os ambientes espetaculares onde por vezes são transacionados fizeram com que, para um número crescente de consumidores, a ida às compras deixasse de ser uma atividade básica ligada à satisfação de necessidades e se transformasse numa agradável experiência de lazer (Gardner \& Sheppard, 1989).

Não menos significativas são as mudanças ao nível da organização espacial. À aliança secular com a centralidade e a proximidade, na base da qual se formaram sistemas hierárquicos de centros de comércio, sucederam-se as relações de conveniência dominadas pela acessibilidade e a facilidade de estacionamento, conduzindo à descentralização da atividade comercial e à des-hierarquização do sistema de centros; e mais recentemente, através da exploração das distâncias psicológicas e do potencial sedutor da hiper-realidade, chegou a vez do distanciamento do espaço público da cidade. Este processo de descentralização dos tecidos comerciais e exploração do simbolismo e das ambiências dos lugares de consumo resultou num enfraquecimento do papel do centro da cidade e dos bairros tradicionais, enquanto espaços de compra e abastecimento. Nos tempos pós-modernos e hiper-modernos, o interesse dos investidores da distribuição reside cada vez mais nos subúrbios. Irrigados de vias rápidas, preços de solo mais baixos e sem património construído a preservar, estes espaços dificilmente encontram concorrentes à altura adequados à implantação dos mega projetos explorados pelos grupos imobiliários com interesses na distribuição. Por isso, é na periferia, por vezes no meio do nada, que os grandes complexos comerciais tendem a ser edificados e uma grande fatia de consumidores motorizados, principalmente, aos fins de semana, se abastece de bens de primeira necessidade, faz as compras ocasionais, convive e se diverte.

Por último, uma observação atenta das mudanças mais recentes dos sistemas comerciais torna evidente que a sua reestruturação regista uma passagem progressiva dos "espaços de comércio" para os "lugares de consumo", tendo como trave mestra o simbolismo das mercadorias e as ambiências das lojas (Cachinho, 2005). Esta passagem não é destituída de significado. Bem pelo contrário, condensa no seu interior todas as metamorfoses sofridas pelas lojas, levadas a cabo por sofisticadas técnicas de marketing e 
design através das quais se procura seduzir os indivíduos-consumidores e transformar as lojas em mercadorias, para serem "consumidas", à semelhança dos objetos, das marcas e dos produtos transacionados no seu interior.

O papel do simbolismo na construção da identidade dos estabelecimentos comerciais avalia-se melhor se tivermos em consideração os princípios que ao longo das últimas décadas têm orientado a mudança dos sistemas comerciais, com destaque para a venda a retalho. $\mathrm{O}$ consumo fordista respondia à lógica moderna dos mercados de massas, homogeneizados e padronizados por uma tecnologia que encontra na produção de grandes séries a condição primordial para o embaratecimento dos produtos e a ampliação dos mercados (Alonso, 1999). A condição pós-moderna altera esta lógica, não tanto através da sua superação, mas antes pela via da complexificação, fragmentando os tradicionais lineares numa diversidade de nichos, orientados para diferentes valores e estilos de vida, que em último grau tendem para a individualização. Nesta nova lógica mercantil, o preço e a qualidade dos produtos, que durante o projeto modernista determinam a segmentação da oferta e a hierarquização das lojas, perdem parte do seu valor estratégico. Para responder às exigências dos consumidores, que em diálogo com os objetos e as lojas procuram construir a sua identidade, os retalhistas mais dinâmicos segmentam a oferta em múltiplos nichos de mercado, usando todo um manancial de valores culturais, construídos sobre práticas ecléticas e paradoxais.

Esta nova forma de perspetivar o consumo e os consumidores tem sido acompanhada por profundas mudanças na conceção dos espaços comerciais e nas funções. Naturalmente, pode-se dizer que a função das lojas não é outra que a de vender mercadorias e, mediante a troca, reproduzir o capital dos investidores. Porém, para que possam continuar a desempenhar com eficiência tal função, cada vez mais se torna necessário que estas pareçam tudo menos espaços de transação. Na sociedade contemporânea, os estabelecimentos estão a deixar de ser meros lugares de troca, de espaços onde as pessoas se deslocam para satisfazer as suas necessidades de aprovisionamento. Nem mesmo nos hipermercados, formato paradigma do consumo de massas, essa lógica parece subsistir. À imagem de outras unidades comerciais, estes não só vendem mercadorias como estão a transformar-se, em si mesmos, num objeto passível de ser consumido. Mais do que bens e serviços, através da arquitetura, do design, das ambiências, das marcas, das insígnias, do espetáculo e do simbolismo dos objetos, um grande número de estabelecimentos está empenhado em oferecer aos consumidores verdadeiras experiências de vida (Ritzer, 1999; Cachinho, 2002; Mikunda, 2006). Aqui as pessoas abastecem-se, desfrutam de momentos de lazer, satisfazem as suas necessidades de consumo, mas também realizam desejos, tornam reais sonhos e fantasias. Isto acontece porque na cidade contemporânea nenhum lugar, público ou privado, parece conseguir agradar, seduzir ou granjear o interesse dos indivíduos se não lhes conseguir oferecer experiências de vida. Numa cidade onde tudo parece girar em torno do "consumo de espectáculos, de espectáculos de consumo, do consumo de signos e de signos de consumo" (Lefèbvre, 1969: 150), as experiências estão a transformar-se numa espécie de refúgio coletivo. 
Em suma, a revolução comercial está a gerar nas nossas cidades um sistema polarizado por dois tipos de espaços comerciais. De um lado, deparamo-nos com um pequeno número de lojas, que investindo na mise-en-scène das mercadorias, na teatralidade das imagens e na simulação do ambiente construído, exploram os musées imaginaires dos consumidores, oferecendo-lhes autênticas experiências de vida. Do outro lado, encontramos um grande número de unidades comerciais que, desprovidas de signos e valor simbólico significativo para os consumidores, continuam a ser percebidos como simples espaços de trocas e abastecimento. Usando uma velha classificação modernista, enquanto o primeiro grupo de estabelecimentos deixou o mundo tangível dos produtos para explorar a hiper-realidade dos signos e dos símbolos e através destes venderem sonhos aos consumidores, o segundo grupo permanece ligado ao mundo terreno dos produtos orientados para a simples satisfação das necessidades básicas dos consumidores que, por vezes, já nem existem, a não ser na mente de alguns vendedores (Cachinho, 2002). Enquanto o primeiro grupo de unidades comerciais está a crescer vertiginosamente e todos os dias conquista novos ramos de atividade e territórios na cidade, o segundo encontra-se em claro declínio, especialmente nos setores da cidade desprovidos das amenidades ambientais e culturais valorizadas pela sociedade de consumo ou então povoados pelos consumidores economicamente mais desfavorecidos.

\section{PLANEAR O COMÉRCIO PARA A MUDANÇA}

O objeto de estudo do projeto REPLACIS consistia nas mudanças dos sistemas comerciais urbanos e os fatores que as originam, assim como as políticas públicas adotadas para regular a atividade comercial. A investigação foi conduzida através das lentes da resiliência e da sustentabilidade urbana, de acordo com um conjunto de dimensões analíticas e indicadores que combinam a pesquisa quantitativa e qualitativa, inspirando-nos em estudos desenvolvidos, nomeadamente, por Callaghan \& Colton (2008); Scerri \& James (2009); Knox \& Mayer (2009); Ravenscroft (2000); Balsas (2004); Balsas, Kotval \& Mullin (2004). Sendo o comércio um elemento chave da produção e experiência da cidade contemporânea, a sustentabilidade urbana pode ser associada à preservação de sistemas comerciais alicerçados na diversidade de formatos de lojas, ramos de atividade e ambientes comerciais. Neste contexto, foram considerados resilientes os sistemas que demonstrassem capacidade para se adaptarem às mudanças do ambiente económico, social e cultural, sem que tal adaptação modificasse qualitativamente as suas funções; isto é, fossem capazes de continuar a responder, com eficácia, às necessidades dos diferentes grupos de consumidores, incluindo os mais desfavorecidos. A par destas ideias chave, o projeto apoiou-se também no pressuposto que as distintas formas de comércio e áreas comerciais na cidade são dotadas de diferentes níveis de vitalidade e resiliência, e que estes podem ser reforçados pelas políticas de planeamento setoriais e territoriais. $\mathrm{O}$ incremento da capacidade de resposta dos comerciantes e das áreas de comércio mais vulneráveis favorece a restauração do equilíbrio dos 
sistemas comerciais, fomentando a sua resiliência e, por essa via, o desenvolvimento mais sustentável das cidades.

Balizado por estes princípios, o Projeto REPLACIS visou alcançar o seguinte conjunto de objetivos:

- Analisar as mudanças do comércio e as políticas que lhe estão associadas, e avaliar o potencial destas na revitalização dos sistemas comerciais e na promoção da sustentabilidade urbana.

- Refletir sobre o papel do comércio na produção e vivência da cidade.

- Conceber um quadro conceptual e metodológico adequado à avaliação da resiliência dos sistemas comerciais, de apoio às políticas públicas ligadas ao comércio.

- Testar os níveis de resiliência dos sistemas comerciais, mediante a aplicação de um conjunto de indicadores a diferentes áreas comerciais.

Para alcançar estes objetivos a investigação beneficiou de três âncoras. A primeira consistiu na dupla perspetiva selecionada para ler os sistemas comerciais e o papel "produtivo" do comércio e do consumo na cidade. As paisagens comerciais foram analisadas, por um lado, enquanto artefactos materiais de transação de bens e serviços, e por outro lado, enquanto espaços mentais, lugares de experiências e distinção social, ligados ao "segundo sentido" do consumo gerado pelo valor signo das mercadorias e pelo simbolismo dos espaços comerciais. Enquanto a primeira perspetiva olhou para o mundo visível, detendo-se nos valores de troca e uso das áreas comerciais, a segunda explorou o mundo invisível do consumo e estendeu os conceitos de valor simbólico e de signo de Baudrillard (1972) às lojas e às áreas comerciais. No essencial, tratou-se de combinar as perspetivas behaviorista e da cognição social da decisão dos comerciantes e dos consumidores, tradicionalmente utilizadas na interpretação das práticas dos atores, com a perspetiva da Teoria da Cultura do Consumo (TCC), de Arnould e Thompson (2005), na qual os comerciantes e os espaços comerciais tendem a ser vistos pelos consumidores como campos onde recursos operantes interatuam, mobilizados pelos consumidores na realização dos seus projetos de vida (Arnould, 2005).

A segunda âncora consistiu no mix de métodos usados na avaliação das vulnerabilidades e da capacidade de adaptação dos sistemas comerciais. Esta combinação de métodos permite a produção de dois tipos de indicadores. O primeiro, consentâneo com a investigação extensiva, baseia-se em métodos quantitativos e orienta-se para a avaliação das dinâmicas económicas, sociais e físicas das áreas comerciais. O segundo, congruente com a investigação intensiva, apoia-se na realização de entrevistas a agentes privilegiados e na análise de casos de estudo ilustrativos de diferentes tipos de áreas comerciais da cidade. A informação, de cariz qualitativo, é recolhida através da observação in loco, mediante a aplicação de questionários, entrevistas e fichas de observação, a comerciantes e consumidores, e visa a avaliação das representações dos principais atores sobre as áreas comerciais.

Por último, a investigação apoiou-se também na análise de um conjunto de áreas comerciais, inseridas em distintos contextos urbanos, e beneficiou da aprendizagem social proporcionada pela investigação colaborativa, interdisciplinar e internacional. 
As abordagens recentes da sustentabilidade urbana tendem a reivindicar o desenvolvimento de cidades mais compactas, que explorem os usos mistos e sejam dotadas de áreas centrais dinâmicas e bairros residenciais preservados. No entanto, a tendência que se observa não só parece ir no sentido inverso como, com o incremento da globalização, a maioria das cidades mostra claros sinais para uma certa homogeneização e partilha dos mesmos problemas e desafios. Ao contrário do que seria de esperar, a competição entre as cidades a nível internacional pela atração de fluxos de capital e pessoas tem conduzido as mesmas para uma certa estandardização, seja das paisagens e dos lugares de comércio e consumo, com a difusão das mesmas insígnias, marcas e formatos de lojas, seja ao nível das políticas públicas, nomeadamente as ligadas à regeneração urbana que usam como locomotivas o comércio, o consumo e a cultura. Um fenómeno, de resto, que vários autores já denunciaram, referindo-se ao mesmo de várias formas: produção de monotonias «seriais» e «recursivas» (Boyer, 1988), "utopias degenerativas" do capitalismo global (Harvey, 2000); "espaços da urbanalização" (Muñoz, 2008).

Contudo, não faltam exemplos que nos levam a crer que todas as cidades são diferentes, fazendo com que uma política bem-sucedida num lugar possa fracassar noutro, sobretudo se aplicada em contextos geográficos com valores culturais e sistemas de governança diferentes. Jayne (2006) dá-nos conta desta situação no Reino Unido, a propósito da promoção da competitividade económica das cidades recorrendo a programas de regeneração ancorados na cultura e no consumo. É verdade que na sociedade urbana pós-moderna, a diversidade de oportunidades de consumo oferecida por uma cidade é um fator chave da sua competitividade. Mas importa lembrar que os projetos de regeneração urbana são sempre levados a cabo em contextos de relações sociais e formas de sociabilidade muito específicas, que podem representar uma mais-valia para o sucesso dos programas ou atuar no sentido inverso. Deste modo, através da investigação transnacional, o projeto REPLACIS procurou avaliar o que há de comum e distinto nos vários países, com o objetivo de definir um conjunto de indicadores de desempenho passíveis de aplicação aos sistemas comerciais das cidades de diferentes contextos sócio-espaciais. Mediante a aprendizagem social, a comparação de casos de estudo e do confronto de pontos de vista dos especialistas, bem como dos decisores políticos e dos comerciantes, torna-se possível avaliar as vulnerabilidades e a capacidade de adaptação dos sistemas comerciais urbanos e refletir sobre as opções de política mais adequadas à promoção da sustentabilidade urbana.

\section{O quadro conceptual e metodológico}

As experiências em relação às mudanças da vitalidade e viabilidade económica dos sistemas comerciais, bem como ao planeamento e à governança urbana, permitem-nos concluir que o quadro conceptual e metodológico para avaliar a resiliência dos sistemas comerciais necessita de considerar três grandes domínios de intervenção: (i) as dinâmicas do aparelho comercial da cidade, quanto ao perfil dos comerciantes, mix de atividades, formatos das lojas e rede de tipos de centros de comércio; (ii) os atributos da cidade 
no que concerne ao seu posicionamento na hierarquia urbana, o ambiente físico construído e as características demográficas e sociais das áreas comerciais; e (iii) as formas de governança, as políticas públicas e o planeamento da cidade com influência no desenvolvimento da atividade comercial. Cada um destes domínios inclui áreas de interface nos quais se identificam indicadores de desempenho indispensáveis ao diagnóstico da vitalidade e viabilidade dos centros de comércio da cidade, bem como os fatores que necessitam ser tidos em conta e geridos estrategicamente. Através deste diagnóstico, análise prospetiva e monitorização da evolução dos centros de comércio da cidade torna-se possível planear o sistema comercial para a mudança, adequando-o às necessidades dinâmicas dos consumidores e dos comerciantes e, por essa via, reforçar tanto os seus níveis de resiliência como a coesão social e a sustentabilidade da cidade. Do ponto de vista da resiliência, a abordagem destes três domínios de intervenção, bem como das suas zonas de interface, apenas ganha verdadeiro sentido quando moldada pelas lentes e as perspetivas do tempo, da escala geográfica e dos atributos do espaço e do lugar. É esta multidimensionalidade temporal e espacial da abordagem que garante a captação e monitorização das mudanças das áreas comerciais, e que as respostas dos stakeholders do setor público e privado, no quadro de uma plataforma colaborativa, podem ir ao encontro das necessidades dos sistemas comerciais, reduzindo as suas fragilidades e melhorando a sua vitalidade (fig.1).

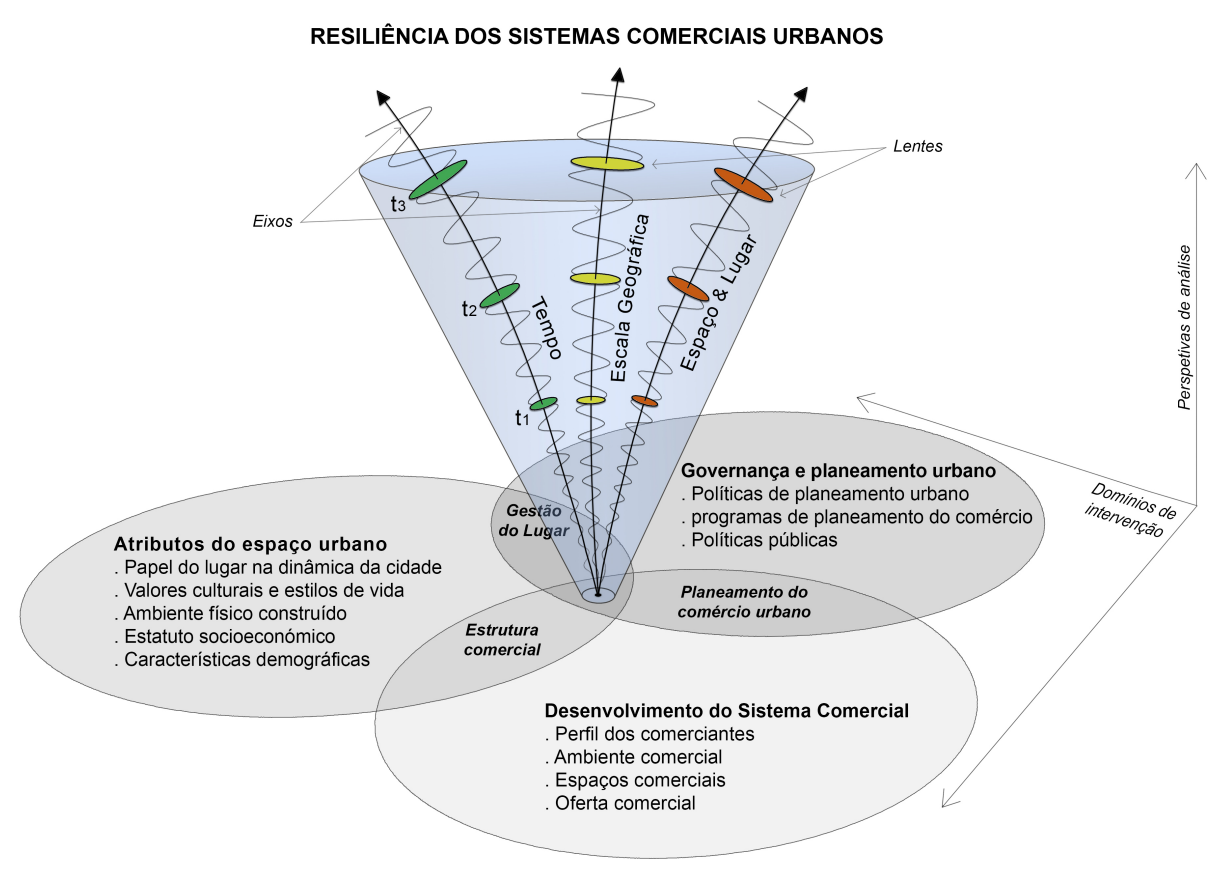

Fig. 1 - Quadro conceptual de avaliação da resiliência dos sistemas comerciais urbanos.

Fig. 1 - Conceptual framework for the resilience evaluation of urban retail systems. 
Os atributos do aparelho comercial em relação ao mix de atividades, aos formatos das lojas, ao perfil dos comerciantes e à organização espacial da oferta, constituem um domínio basilar na avaliação da resiliência dos sistemas comerciais. A sua análise implica, na nossa perspetiva, a conjugação no mínimo de duas escalas geográficas: por um lado, a aglomeração urbana e o seu hinterland; e, por outro lado, os diferentes tipos de centros do sistema comercial. A escala macro permite-nos avaliar o sistema em termos de níveis de concentração empresarial, internacionalização da oferta, modernização das lojas, posicionamento no ciclo de vida dos formatos comerciais e níveis de descentralização da atividade comercial. Em última análise, esta escala geográfica informa-nos sobre a competitividade global do sistema comercial, bem como da sua vitalidade e viabilidade económica.

A escala local, referente a cada centro ou área comercial, deve ser lida em articulação com a sua posição no sistema comercial e as funções que supostamente devem desempenhar no abastecimento dos consumidores. Neste contexto, além do centro da cidade, importa distinguir mais dois tipos de centros: (i) os de conveniência ou proximidade, orientados para a satisfação das necessidades básicas da população, e por isso com ligação estreita à oferta de bens de consumo de aquisição frequente; e (ii) os centros de influência regional, orientados para a oferta de uma grande diversidade de bens e serviços, a maioria de aquisição ocasional. Naturalmente, nas cidades de maior dimensão existem outros tipos de centros associados, umas vezes às modernas formas de distribuição, outras a processos de especialização funcional, e outras vezes ainda ao capital simbólico que confere identidade aos espaços, como acontece, por exemplo, com o comércio explorado pelas minorias étnicas. No entanto, estas áreas além de obedecerem a uma lógica de funcionamento diferente, em termos da área de influência acabam por se comportar como centros de influência regional.

Com papéis distintos no sistema, a avaliação ao nível de cada área comercial deve procurar estimar a sua vitalidade, passível de medição através de um conjunto de indicadores relativos aos estabelecimentos (taxa de rotatividade das lojas, oferta de espaços comerciais e respectivo preço por $\mathrm{m}^{2}$, número de lojas vazias, taxas de cessação de atividade e de abertura de novas lojas, ...), ao mix de ramos de atividade, ao perfil dos comerciantes em matéria de formação, qualificação profissional e empreendedorismo, e ao grau de satisfação dos consumidores com a oferta e outras amenidades, mobilizadas pelos indivíduos-consumidores na realização dos seus projetos de vida.

As características da cidade, em termos do potencial demográfico e do posicionamento na rede urbana e nos fluxos de capitais, pessoas e informação, por um lado, e dos tipos de centros de comércio e serviços, quanto ao ambiente construído e aos atributos demográficos e sociais, por outro, são outro domínio essencial a ter em conta na avaliação da resiliência dos sistemas comerciais. Sobre o papel das primeiras pouco há a acrescentar, a não ser que destas depende a complexidade dos sistemas comerciais, nomeadamente, em termos de número e tipo de centros, sua disposição no território e nível de internacionalização da oferta, e naturalmente os fatores que interferem com a sua produção, organização e funcionamento. Na realidade, o conhecimento da condição das cida- 
des nestes campos afigura-se mesmo como um pré-requisito da conceptualização do problema da resiliência dos sistemas comerciais. Aqui, a reflexão de Massey (1993) sobre o espaço e a geometria do poder constitui um argumento de peso. Esta autora mostra-nos como os indivíduos, os grupos, as cidades e as regiões se posicionam de forma muito diferente na rede de fluxos e conexões políticas, económicas, sociais e culturais do processo da globalização. Enquanto algumas ocupam uma posição de centralidade, participando inclusive na sua produção e difusão, outras detêm uma posição subalterna, limitando-se a receber os mesmos e a colher os seus impactos.

Se o nosso objetivo consiste em compreender o dinamismo dos sistemas comerciais e as forças responsáveis pelas suas transformações, é fundamental que se tenha consciência da posição e das ligações que a cidade estabelece nestas escalas geográficas. Massey (1993) mostra-nos como a teorização da mudança das cidades se encontra ligada a uma conceptualização bem-sucedida de construção global de lugar. Enquanto nós das redes de fluxos de capitais e ideias, as cidades são construções sociais dinâmicas resultantes de processos históricos em que diferentes práticas políticas, económicas e culturais esculpiram o seu carácter. Tal entendimento sugere que a capacidade das cidades para competirem em nós específicos da hierarquia urbana pós-industrial é, em parte, determinada pelas geografias do consumo (e da produção) que operam em determinadas escalas espaciais (Jayne, 2006). Se deslocarmos o nosso objeto de análise das cidades para os sistemas comerciais, o valor explicativo desta argumentação em nada é beliscado. A sua natureza não só é, em parte, um produto do posicionamento da cidade na hierarquia urbana, contemplando esta a interação de processos em diferentes escalas geográficas, como reflete também, em cada momento, a evolução das práticas dos diferentes atores, incluindo as concebidas para responder aos desafios da competitividade levantados pelos processos da globalização económica e cultural.

No entanto, a avaliação da resiliência dos sistemas comerciais implica, necessariamente, uma análise mais pormenorizada, que seja capaz de dar conta do dinamismo dos diferentes tipos de centros de comércio da cidade. Na verdade, sabendo que a revolução comercial não afeta de igual modo os diferentes ramos de atividade e áreas comerciais, é sobretudo a este nível que o exercício de avaliação levanta mais desafios à sua conceptualização. Sendo a cidade e o comércio sistemas dinâmicos por natureza, é natural que o mesmo comporte, num dado momento, áreas comerciais em diferentes fases do seu ciclo de vida, à semelhança dos bairros que configuram a sua organização. Assim, de acordo com o modelo de desenvolvimento das áreas comerciais intra-urbanas de Berry (1963), é muito provável que qualquer sistema comercial, por circunstâncias de natureza económica, física, friccional e funcional seja, em determinado momento, formado por áreas (i) em fase de criação ou estabelecimento (que acontece, por exemplo, com o aparecimento de novas urbanizações); (ii) em fase de expansão, em que a prosperidade das primeiras lojas provoca a atração de outras e de novas funções; (iii) em fase de declínio, pautada pela estagnação da entrada de novas funções e novas lojas e o desaparecimento de outras; e (iv) em fase de sucessão de funções, quando o mal-estar dos negócios e a degradação física das lojas tornam a área pouco atrativa e marginal aos atos da compra e do abasteci- 
mento. A estas quatro fases identificadas por Berry, acrescentamos nós outra, frequente nas cidades europeias, que designamos por fase de regeneração ou revitalização, quase sempre associada à revalorização de lugares da cidade dotados de elevado valor simbólico ou ligada a programas públicos de requalificação urbana, exemplificados pelos centros das cidades, as frentes de água e algumas áreas industriais e portuárias desativadas, dotadas de amenidades com interesse para o comércio, o consumo e o lazer.

Sendo um objetivo do projeto REPLACIS planear o sistema comercial das cidades para a mudança e a escolha dos consumidores, importa a este nível, em primeiro lugar, identificar através de um conjunto de indicadores as fases em que se encontram os diferentes tipos de centros de comércio da cidade, assim como os problemas que impedem a adaptação às mudanças contextuais e limitam as oportunidades de abastecimento dos consumidores. Em segundo lugar, elaborado o diagnóstico da vitalidade dos diferentes tipos de centros e apurado o grau de satisfação dos consumidores, torna-se necessário identificar os fatores que estão na base do seu sucesso ou insucesso, de forma a desenvolver as ações que possam melhorar os níveis de desempenho e, se possível, combater o seu declínio.

Berry (1963) identificou quatro grupos de fatores que frequentemente estão associados à perda de vitalidade, declínio e morte das áreas comerciais, que podem ser mobilizados na avaliação da resiliência dos sistemas comerciais. Em primeiro lugar, o declínio pode dever-se a razões de natureza económica. A perda de população residente ou a sua mudança de estatuto socioeconómico, quando associada a uma redução do poder de compra, a perda de competitividade das lojas e a incapacidade dos comerciantes adaptarem a oferta aos novos clientes, estão entre os fatores mais frequentes. $\mathrm{O}$ declínio motivado por estas razões manifesta-se na paisagem sobretudo através do aumento do número de lojas vazias, a mudança da oferta e o desaparecimento das lojas de standing mais elevado. Em segundo lugar, o declínio pode estar associado a fatores de ordem física. O envelhecimento das construções e dos locais pode conduzir a uma degradação material das áreas comerciais. Com o acentuar desta degradação, os edifícios tendem a se tornar inseguros e indesejáveis, e por estes motivos os clientes deixam de frequentá-los, com reflexos na imagem e dinamismo de toda a área comercial. $\mathrm{O}$ terceiro grupo de fatores é de natureza friccional e surge quase sempre ligado ao empobrecimento do estatuto e à degradação do ambiente dos bairros, que acabam com frequência por virar focos de condutas desviantes: a violência, o delito, a delinquência, o vandalismo... Estas manifestações, associadas a outros fatores, como as dificuldades ao nível das acessibilidades, circulação e estacionamento, e o sentimento de insegurança, tendem a tornar estas áreas indesejáveis e nefastas para o exercício do comércio. Por último, o quarto grupo reúne os fatores de cariz funcional. Algumas áreas entram em declínio porque muitos comerciantes, descapitalizados, se mostram incapazes de reagir às mudanças que afetam a atividade comercial. Sem formação e os recursos necessários para se modernizarem, inovarem ou simplesmente ajustarem a oferta às mudanças das necessidades dos consumidores, acabam por perder competitividade e cessar o exercício da atividade. 
Tendo por base os quatro tipos de fatores identificados por Berry (1963) para o declínio das áreas comerciais, Meir e Marcus (1983) desenvolvem um quadro conceptual que permite avaliar a vitalidade e viabilidade económica das áreas comerciais nos espaços metropolitanos, mobilizando apenas quatro dimensões analíticas: a taxa de lojas vazias, $o$ preço dos espaços comerciais, a qualidade das mercadorias e as condições físicas. As áreas comerciais na cidade são então classificadas em termos do comportamento que manifestam nestas dimensões, tendo como referência, a presença/ausência do fenómeno, ou então a posição que ocupam em relação à média da cidade.

Desnecessário será dizer que as áreas comerciais bem-sucedidas, que revelam grande vitalidade e dinamismo, encontram-se quase sempre no polo oposto das áreas em declínio em relação às dimensões de análise explicitadas. Do ponto de vista económico, são áreas em que, na fase de maturidade, a procura por espaços residenciais e comerciais excede largamente a oferta, elevando as rendas para preços que apenas a população de estatuto socioeconómico mais alto e as funções com mais prestígio, capital simbólico ou maior rendibilidade são capazes de suportar. A ação dos fatores económicos revela-se na paisagem mediante uma progressiva affinage do mix comercial, a melhoria dos níveis de standing e modernização das lojas, a presença de cadeias de prestigiadas marcas e insígnias, por vezes em regime de franchising, e o aumento dos preços das rendas dos espaços comerciais.

Em relação ao ambiente construído, as áreas comerciais de sucesso podem estar associadas a espaços morfologicamente muito distintos, dependendo, em grande medida, da época da sua construção e localização na cidade. No entanto, todas tendem a apresentar em comum o bom estado de conservação da generalidade dos edifícios, a qualidade do espaço público e do mobiliário urbano, e ainda um conjunto de amenidades relacionadas com a acessibilidade, a circulação e a facilidade de parqueamento. A influência dos fatores físicos na vitalidade das áreas comerciais faz-se sentir, em primeiro lugar, ao nível da elegância, distinção e capacidade de comunicação da arquitetura, do design e das ambiências geradas por muitas lojas, estrategicamente concebidas para atrair a atenção e seduzir os indivíduos-consumidores. Em segundo lugar, manifestam-se também ao nível da apropriação do espaço público pelos consumidores. Dotado das qualidades humanas e das amenidades favoráveis ao passeio, ao convívio, ao encontro com o outro, ou à simples deambulação, o espaço público parece nunca esgotar as razões para a sua frequência, pelo que os indivíduos-consumidores tendem a ver no mesmo o lugar ideal para passar uma boa parte do seu tempo de lazer. Gehl e GemzØe (2004) deixam bem claro, a partir da experiência de Copenhaga, o potencial que o espaço público pode conter no sucesso do centro da cidade e de outras áreas comerciais e de lazer, quando não mesmo da cidade na sua globalidade.

Os contributos dos fatores de cariz friccional para o sucesso das áreas comerciais são sobretudo visíveis nos setores da cidade que foram objeto de regeneração urbana, acompanhados de processos de nobilitação residencial e funcional. Quando passeamos pelas ruas da cidade e apreciamos as amenidades do espaço público e a espetacularidade de alguns edifícios, usados como locomotivas dos projetos de intervenção, raramente temos 
consciência dos problemas que estes escondem. Na realidade, estas intervenções afetam profundamente tanto a habitação como a atividade comercial pré-existente. A habitação é influenciada em termos físicos e sociais. A população de menores recursos económicos e estatuto social é desalojada, através da demolição das casas mais modestas e em elevado estado de degradação, ou através do aumento dos preços das novas habitações, impossíveis de suportar por este estrato da população. Existem muitas formas de desalojamento geradas pelos projetos de regeneração urbana envolvendo processos físicos ou o aumento dos preços gerado pela especulação imobiliária. No entanto, todos partilham em comum o facto de substituírem habitação barata e de condições modestas, ocupada por famílias de baixos rendimentos e/ou socialmente excluídas, por habitações de luxo e elevado estatuto, dirigidas para as famílias de rendimentos elevados, que caracterizam o novo gentrifier (Mendes, 2006; Malheiros et al., 2013). Este processo que afeta a habitação é também válido para o comércio. Mais exigentes, os novos residentes e a população que visita estas áreas conduzem a uma mudança da oferta e do perfil dos comerciantes. Naturalmente, neste processo de invasão-sucessão, apenas permanecem na área regenerada os comerciantes mais aptos, dotados das competências e dos recursos que lhes permitem fazer a transição para o novo ambiente e a nova clientela, que reside, trabalha ou simplesmente visita o local para fazer compras ou nele passar alguns momentos de lazer.

Por último, em relação aos fatores funcionais, as áreas comerciais bem-sucedidas tendem a apresentar um elevado dinamismo funcional, mesmo na fase de plena maturidade. Pela forma como são disputadas, nestas encontram-se quase sempre os comerciantes mais dinâmicos, dotados da formação e dos recursos necessários à adaptação à mudança. Por esta razão, antes de alcançarem a fase de maturidade, é frequente que nestas se registem elevadas taxas de rotatividade dos estabelecimentos e uma mudança significativa do uso do solo e das funções que se desenvolvem, quase sempre associadas a um refinamento do mix comercial.

O terceiro domínio do modelo de análise encontra-se ligado à intervenção dos poderes públicos, na qual se podem distinguir quatro grandes eixos. O primeiro prende-se com a atividade de regulação. Neste campo, importa saber, como é que as várias instituições, sem coartarem a inovação e a modernização dos sistemas comerciais, os têm gerido de modo a garantir o seu equilíbrio em termos de formas de comércio, formatos de lojas e tipo de empresas. O segundo eixo diz respeito à regulamentação do sistema comercial. Incluem-se aqui os diplomas legais que enquadram o exercício da atividade comercial, que pela forma como influenciam a decisão dos investidores acabam por ser responsáveis pela evolução dos sistemas comerciais, nomeadamente, em relação aos formatos das lojas e do seu arranjo espacial. O terceiro eixo está relacionado com o ordenamento do território e o urbanismo, seja no plano legislativo, através da aprovação de leis de forte pendor territorial relativas, por exemplo, à implantação das grandes superfícies, seja mediante a contemplação do setor nas principais figuras de planeamento de cariz territorial, seja através da criação de planos orientados para a requalificação da atividade comercial e urbana, mediante a constituição de parcerias público-privado, dos quais fazem parte, em Portugal, os Projetos Especiais de Urbanismo Comercial (PEUC's), no Reino Unido, os 
Town Centre Management Schemes, em França, as operações Centre 2000, ou em Espanha, os Centros Comerciales Abiertos (CCA). Por último, o quarto eixo de intervenção consiste na dinamização empresarial, seja mediante o lançamento de programas de apoio ao desenvolvimento sustentado da competitividade das empresas, seja pela via da atribuição de incentivos de natureza financeira e fiscal, relacionados com a criação de postos de trabalho, o reinvestimento dos valores de realização, ou as ações de cooperação ou concentração.

Através da atividade de regulação, os poderes públicos podem desempenhar um papel crucial na manutenção do equilíbrio dos sistemas comerciais, reforçando os seus níveis de viabilidade e resiliência. O quadro I fornece uma breve sinopse da evolução das políticas para o setor do comércio a nível nacional, nos últimos 50 anos. Nele se pode observar que tanto o seu conteúdo e objetivos como o quadro legislativo regulamentador se alteram substancialmente com o contexto de intervenção, refletindo as mudanças que se operaram no sistema. Em grandes linhas, trata-se de uma atitude essencialmente reativa, que tem como objetivo disciplinar a difusão territorial de novos empreendimentos com dimensão relevante, que possam ameaçar a competitividade dos pequenos comerciantes e a vitalidade dos centros tradicionais de comércio da cidade. No entanto, outras orientações são possíveis, explorando estratégias mais integradas e pró-ativas, em íntima articulação com o poder local, nas quais se podem enquadrar, por exemplo, as iniciativas relacionadas com a criação dos PEUC e das Unidades de Acompanhamento e Coordenação (UAC) e ainda do gestor de centro urbano.

Guy (2007) fornece a respeito das políticas públicas para o comércio um excelente testemunho a partir da avaliação crítica que faz da sua evolução na Inglaterra. Entre outros aspetos, mostra-nos como nas últimas décadas estas se têm orientado para a revitalização dos centros urbanos (town centres first), a promoção do desenvolvimento sustentado mediante a redução das viagens motorizadas para fins de abastecimento, a melhoria do design do ambiente físico e as boas relações de vizinhança com o tecido comercial preexistente, a necessidade de melhorar a qualidade da oferta nas áreas socialmente carenciadas, e a obrigatoriedade de demonstrar a relevância dos novos projetos para a oferta local. Os impactes desta orientação das políticas não se fizeram esperar. Em primeiro lugar, diminuíram os projetos de grande dimensão localizados nas áreas suburbanas e aumentou a procura por localizações mais centrais. Em segundo lugar, devido ao carácter restritivo para os projetos que se pretendem localizar na periferia, o espaço disponível favorável à expansão geográfica de alguns formatos, como os retail parks, diminui drasticamente. Esta redução conduziu a um aumento do preço do solo para estes fins e com este a uma "gestão ativa" por parte dos promotores, tornando os empreendimentos mais eficientes e atrativos para os consumidores. Em Portugal, de acordo com o conteúdo da Portaria 417/2009, de 16 de abril, a política para o setor parece ir agora no mesmo sentido. A implantação de novos projetos passa não só pelo parecer favorável de diferentes agentes, como a aprovação está dependente de condições que dificultam a localização na periferia, sobretudo quando afetam a mobilidade e o ambiente (Fernandes, 2009). 
Quadro I - Evolução das políticas de desenvolvimento do comércio em Portugal, 1960-2010.

Table I - Evolution of retailing policy development in Portugal, 1960-2010.

\begin{tabular}{|c|c|c|c|}
\hline Parâmetros & $\begin{array}{c}\text { Passiva } \\
(1960-1980)\end{array}$ & $\begin{array}{c}\text { Reativa } \\
(1980-1999)\end{array}$ & $\begin{array}{c}\text { Ativa } \\
(2000-2012)\end{array}$ \\
\hline $\begin{array}{l}\text { Contexto de } \\
\text { intervenção }\end{array}$ & $\begin{array}{l}\text { - Domínio dos pequenos } \\
\text { comerciantes } \\
\text { - Protagonismo das áreas } \\
\text { centrais e do comércio } \\
\text { de bairro }\end{array}$ & $\begin{array}{l}\text { - Competição entre pequenos } \\
\text { comerciantes e cadeias de } \\
\text { distribuição } \\
\text { - Difusão das grandes superfícies } \\
\text { - Dialéctica centro-periferia } \\
\end{array}$ & $\begin{array}{l}\text { - Crescimento da competição } \\
\text { entre tipos de comerciantes } \\
\text { - Diversificação dos formatos } \\
\text { - Afirmação das lojas e sítios } \\
\text { enquanto lugares de experiência }\end{array}$ \\
\hline $\begin{array}{l}\text { Quadro } \\
\text { legislativo }\end{array}$ & $\begin{array}{l}\text { - Regulamentação do } \\
\text { acesso à atividade e seu } \\
\text { exercício } \\
\text { - Escassas preocupações } \\
\text { territoriais } \\
\text { - Relativo vazio legislativo }\end{array}$ & $\begin{array}{l}\text { - Diplomas relativos à } \\
\text { implantação de grandes } \\
\text { superfícies: } \\
\text { DL 190/89, } 6 \text { junho } \\
\text { DL 258/92, } 20 \text { novembro } \\
\text { DL 83/95, } 26 \text { abril } \\
\text { DL 218/97, } 20 \text { agosto } \\
\text { - Criação de programas de } \\
\text { incentivo à modernização do } \\
\text { comércio: } \\
\text { SIMC e PROCOM } \\
\text { DL 184/94, } 1 \text { de junho }\end{array}$ & $\begin{array}{l}\text { - Diplomas relativos à } \\
\text { implantação de UCDR's } \\
\text { DL 12/2004, } 30 \text { março } \\
\text { - Criação do URBCOM } \\
\text { Portaria 317-B/2000, } 31 \text { de maio } \\
\text { Portaria 113-A/2002, } 7 \text { de } \\
\text { fevereiro } \\
\text { - Criação do MODCOM } \\
\text { Portaria 1297/2005, } 20 \text { de } \\
\text { dezembro } \\
\text { Despacho no } 26 \text { 689/2005 } \\
\text { - Criação das UAC's (Unidades } \\
\text { Acompanhamento e } \\
\text { Coordenação) } \\
\text { - Comissões de Autorização } \\
\text { Comercial - COMAC } \\
\text { Portaria 417/2009, } 16 \text { de abril } \\
\text { DL 21/2009, 19 de janeiro } \\
\text { - Novo Regime Jurídico de } \\
\text { Arrendamento Urbano } \\
\text { Lei no } 31 / 2012,14 \text { de agosto }\end{array}$ \\
\hline Objetivos & $\begin{array}{l}\text { - Exercício e } \\
\text { funcionamento da } \\
\text { atividade comercial }\end{array}$ & $\begin{array}{l}\text { - Regulação da localização e } \\
\text { difusão das grandes superfícies } \\
\text { - Modernização do tecido } \\
\text { comercial } \\
\text { - Impactos territoriais } \\
\text { - Revitalização das áreas centrais }\end{array}$ & $\begin{array}{l}\text { - Regulação do desenvolvimento } \\
\text { das UCDR's } \\
\text { - Avaliação de impactes } \\
\text { territoriais } \\
\text { - Defesa dos tecidos comerciais } \\
\text { tradicionais } \\
\text { - Gestão e sustentabilidade dos } \\
\text { centros urbanos }\end{array}$ \\
\hline
\end{tabular}

Lida na perspetiva da promoção da resiliência dos sistemas comerciais, a mediação dos poderes públicos levanta algumas questões que importa ter em conta. Em primeiro lugar, estando a resiliência do comércio dependente da sua capacidade de adaptação à mudança, as políticas devem ser agilizadas. Só assim podem adaptar-se à mudança quase quotidiana dos sistemas e responder aos desafios levantados pelos novos formatos, cuja cadência de desenvolvimento ultrapassa em muito as medidas de política, tornando o planeamento quase sempre meramente reativo. Em segundo lugar, a manutenção do equilíbrio dos sistemas comerciais, em termos viabilidade dos diferentes tipos de centros e a diversidade de conceitos comerciais exige que a política de planeamento do comércio considere, em estreita articulação, diferentes escalas geográficas. Por último, de acordo 
com as novas funções que o comércio e os espaços comerciais têm sido chamados a desempenhar na vida quotidiana, as políticas de planeamento e governança dos sistemas comerciais devem ser mais articuladas com outras políticas setoriais e territoriais. Esta articulação permite não só aproximar o comércio do modelo de desenvolvimento que se quer para as cidades, como ainda facilitar a avaliação dos impactos dessas políticas na vitalidade dos diferentes centros de comércio e serviços que organizam o sistema.

\section{Os estudos de caso}

Os estudos de caso dizem-nos que os sistemas comerciais não só são dinâmicos como evoluem no tempo sob a influência de fatores endógenos e exógenos aos respetivos sistemas. Este dinamismo coloca-nos um duplo desafio: (i) a necessidade de introduzir o tempo na investigação; e (ii) a capacidade de avaliar o estado de equilíbrio dos sistemas comerciais. Enquanto o primeiro desafio nos remete para uma análise evolutiva das dimensões do sistema, em estreita articulação com os três domínios de intervenção e a sua monitorização ao longo do tempo, o segundo exige que o diagnóstico identifique, num dado momento, o estádio de vitalidade e viabilidade do sistema, bem como as deficiências do seu funcionamento. Neste contexto, estando o equilíbrio do sistema dependente da sua capacidade de resposta às necessidades dos consumidores, importa avaliar, através de diferentes indicadores, o grau de satisfação dos consumidores com o sistema, em termos globais e, sobretudo, em relação aos centros de comércio de proximidade. Apenas na posse deste diagnóstico se pode gerir eficazmente o sistema, adoptando as medidas e as ações mais adequadas à resolução dos problemas. É nesta linha que se inscrevem as orientações da política de planeamento do setor do comércio no Reino Unido, que constam dos Planning Policy Statement 6 e 4 (com destaque para a criação dos Town Centre Health Check Indicators ${ }^{i i}$ ).

Sem desvalorizar a importância das descobertas realizadas pelas equipas nacionais, emergentes da investigação dos casos de estudo, existem pelo menos três produtos do projeto partilhados por todos os membros. Em primeiro lugar, no plano teórico, a investigação contribui para o enriquecimento dos conceitos de resiliência e de sustentabilidade urbana, acrescentando às tradicionais dimensões ecológica e económica as dimensões social e cultural. Para alcançar tal objetivo, a equipa do REPLACIS desenhou um quadro conceptual e metodológico adequado à definição de um conjunto de indicadores de desempenho dos sistemas comerciais intrinsecamente ligados à sustentabilidade urbana. A monitorização dos sistemas apoiada nestes indicadores permite às autarquias compreender as dinâmicas dos sistemas comerciais e a sua capacidade para responder às necessidades de abastecimento dos consumidores, de primordial importância para a sustentabilidade, uma vez que permite aos decisores políticos e a outros atores optar por estratégias orientadas para a adaptação do sistema a futuras mudanças (posição pró-ativa), ou por ações que visam apenas a mitigação dessas mudanças (posição reativa).

Neste domínio, embora o quadro de indicadores definido possa constituir um referencial para a avaliação da resiliência dos sistemas comerciais de cidades inseridas em 
diferentes contextos geográficos, este deve ser adaptado a cada cidade e área cultural. Esta necessidade de adequação deve-se não só ao facto dos sistemas comerciais se encontrarem nos países em fases distintas do ciclo de vida, mas também porque as funções e significado dos espaços comerciais na vida quotidiana da cidade se alteram com os contextos geográficos. Esta questão é sobretudo sensível ao nível do papel de alguns formatos, como acontece com os hipermercados em França (Chevalier, 2007), os grandes armazéns na Suécia (Kärrholm \& Nylund, 2011), ou os centros comerciais na Turquia (Erkip, 2003).

Em segundo lugar, a investigação visou demonstrar a importância das políticas e do planeamento verem no comércio um pilar da resiliência e da sustentabilidade urbana. Se hoje uma boa parte das cidades se produz, organiza e vivencia através dos lugares de comércio e consumo (Jayne, 2006; Miles, 2010), é fundamental que o comércio seja planeado de acordo com o papel que tem na cidade. A análise das múltiplas funções que o comércio e o consumo assumem na sociedade, em particular nas cidades, coloca-nos perante a urgente necessidade de uma profunda mudança na forma como se tem olhado para o setor e interpretado o seu significado. Na realidade, é devido a esta miopia que o comércio tem sido marginalizado nas políticas públicas.

Duas razões fundamentais explicam que se mude de atitude. Em primeiro lugar, é cada vez mais evidente no funcionamento das instituições e nos valores socioculturais que parte do estatuto concedido à produção se tem transferido para o consumo. Na base desta reversibilidade de papéis, encontra-se o facto das mercadorias e mais recentemente as lojas, além do valor de uso e de troca, serem também dotadas de um valor simbólico que lhes é adstrito pelos atos da compra e do consumo. Neste contexto, se a produção de valor continua durante os momentos de consumo, não faz sentido que este continue a ser observado como o fim do processo produtivo. Bem pelo contrário. Vários autores, entre os quais Baudrillard (1975), Featherstone (1991) e Firat e Dholakia (1998), têm demonstrado como na era pós-moderna, o consumo se transformou num ato social mediante $\mathrm{o}$ qual os significados simbólicos, os códigos e as relações sociais são (re)produzidos. Através do consumo as pessoas não só satisfazem as suas necessidades e desejos como se definem a si próprias, criam os seus estatutos, posições e imagens na sociedade. Em segundo lugar, se aceitarmos que a produção e o consumo, em vez de serem processos distintos, constituem apenas diferentes momentos de um mesmo ciclo, então devemos também rever as conceções sobre o papel dos comerciantes e dos operadores de serviços, que de forma mais direta lidam com os consumidores. De simples intermediários dos produtores, por ocuparem uma posição intermédia na cadeia produção-distribuição-consumo, o mais correto é que passem a ser vistos como um dos múltiplos agentes produtivos no ciclo da produção, que comporta sempre as fases de fabrico, distribuição e consumo de objetos, símbolos e signos em lugares e ambientes reais ou virtuais (Cachinho, 2002). Na realidade, foi em grande medida devido ao reconhecimento do papel produtivo do consumo e do comércio pela nova geração de planeadores e fazedores de políticas que muitos projetos de regeneração urbana se têm ancorado no comércio e, em Portugal, os programas de incentivos à modernização do comércio orientem uma vertente para o urbanismo comercial. 


\section{NOTAS FINAIS}

As mudanças sempre moldaram os sistemas comerciais, mas nas últimas décadas a aceleração do seu ritmo e amplitude fizeram com que, em muitas cidades, estes entrassem em desequilíbrio e deixassem de responder, com eficiência, às necessidades dos diferentes grupos de consumidores. Partindo do pressuposto que o comércio é um elemento vital à sustentabilidade urbana, e que o planeamento e as políticas orientadas para o setor podem contribuir para o seu desenvolvimento mais equilibrado, neste artigo apresentámos, em grandes linhas, a investigação que foi desenvolvida no âmbito do Projeto REPLACIS sobre a avaliação da vitalidade e da resiliência dos sistemas comerciais, tendo em vista o incremento da sustentabilidade das cidades.

Em termos de conclusões podem destacar-se alguns pontos. Em primeiro lugar, a leitura das transformações dos sistemas comerciais através das lentes da resiliência tem-se revelado de grande utilidade conceptual, mas também um desafio. A complexidade e o dinamismo dos sistemas comerciais conjugados com as especificidades das relações sociais, económicas e políticas que se tecem nos diferentes contextos culturais e geográficos, dizem-nos que as dimensões analíticas e o conjunto de indicadores concebido para avaliar a vitalidade e os níveis de resiliência dos sistemas necessitam de ser objeto de reflexão e adaptação aos contextos locais, e que a interpretação destes deve pressupor sempre um sentido global de local e de lugar, na acepção que lhes é atribuída por Massey (1993; 1994). Apenas mediante esta adequação se torna possível dar conta das geografias do consumo (e da produção) locais que, em cada momento, se produzem em várias escalas geográficas, ligadas à resiliência dos sistemas, bem como apropriarmo-nos do verdadeiro carácter de cada sistema comercial, por natureza avesso a formas e processos estandardizados e universais.

Em segundo lugar, vendo a resiliência como "a capacidade dos sistemas comerciais se adaptarem às mudanças, às crises e aos choques que desafiam o seu equilíbrio, sem que tal adaptação coloque em causa o desempenho das suas funções de forma sustentável" (REPLACIS, 2010), a mediação dos poderes públicos deve orientar-se, prioritariamente, para: (i) a dotação do sistema dos instrumentos de política que capacitem os comerciantes para a mudança; (ii) a preservação da diversidade, nomeadamente em termos de formatos, tipo de operadores e áreas comerciais. Enquanto os instrumentos de política visam combater a inércia e incentivar a pró-atividade e a adaptabilidade dos comerciantes, por sua vez, a defesa da diversidade de formas de comércio e áreas comerciais garante a possibilidade de escolha aos consumidores, incluindo os mais desfavorecidos.

Por último, sendo a cidade e o comércio sistemas complexos e dinâmicos, a sua sustentabilidade e resiliência beneficiariam em muito da existência de dispositivos de monitorização, para o qual se torna necessário recolher informação relevante de forma sistemática, capaz de dar conta da sua vitalidade e, em consequência, possa ajudar a instruir a mediação dos poderes públicos tendo em vista o restabelecimento do equilíbrio dos sistemas. Dada a cadência com que a inovação e as mudanças se sucedem, para que a monitorização seja possível e sirva, em tempo útil, as tomadas de decisão, é fundamental que 
a informação a obter, nas diferentes escalas geográficas, seja efetivamente relevante, de fácil recolha e contemple não só os interesses dos principais agentes, os comerciantes e os consumidores, mas também sirva o modelo de desenvolvimento da cidade, que se quer sustentável e promova a coesão social.

\section{BIBLIOGRAFIA}

Alonso, L. (1999). Los grandes centros comerciales y el consumidor postmoderno. Distribution y Consumo, 27, 28-30.

Arnould, E. (2005). Animating the big middle. Journal of Retailing, 81 (2), 89-96.

Arnould, E. \& Thompson, C. (2005). Consumer Culture Theory (CCT): twenty years of research. Journal of Consumer Research, 31, 868-883.

Balsas, C. (2004). Measuring the liveability of an urban center: An exploratory study of key performance indicators. Planning Practice and Research, 19 (1), 101-110.

Balsas, C., Kotval, Z. \& Mullin, J. (2004). City center revitalization in the USA, principles, techniques and case studies. In G. Gianfranco, E. Moras, G. Codato (Eds.), L'Approccio integrato alla qualificazione urbana, modelli e strategie di urbanistica commerciale (209-218). Turim: Celide.

Barata-Salgueiro, T. (1996). Do Comércio à Distribuição: roteiro de uma mudança. Oeiras: Celta.

Barata-Salgueiro, T. \& Cachinho, H. (Eds.) (2011). Retail planning for the Resilient City. Consumption and urban regeneration. Lisboa: Centro de Estudos Geográficos.

Baudrillard, J. (1972). Para uma crítica da economia política do signo. Lisboa: Edições 70.

Baudrillard, J. (1975). The mirror of production. St. Louis: Telos.

Berry, B. (1963). Commercial Structure and Commercial Blight: Retail Patterns and Progresses in the City of Chicago. University of Chicago, Research paper, n. ${ }^{\circ} 85$.

Borchert, J. G. (1998). Spatial dynamics of retail structure and the venerable retail hierarchy. GeoJournal, 45, 327-336.

Boyer, M. (1988). The return of aesthetics to city planning. Society, 25 (4), 49-56.

Bromley, R. \& Thomas, C. (1993). The retail revolution, the carless shopper and disadvantage. Transac- tions of Institute of British Geographers, 18 (2), 222-236.

Cachinho, H. (2002). O Comércio Retalhista Português: Pós-modernidade, Consumidores e Espaço. Lisboa: GEPE.

Cachinho, H (2005). O Comércio Retalhista: da venda de bens à oferta de experiências de consumo. In C. Medeiros (Eds.), Geografia de Portugal: Actividades Económicas e Espaço Geográfico, vol. 3 (264-331). Lisboa: Circulo dos Leitores.

Callaghan, E. \& Colton, J. (2008). Building sustainable \& resilient communities: a balancing of community capital. Environment, Development and Sustainability, 10 (6), 931-942.

Chevalier, S. (2007). "Shopping” à la Française : Approvisionnement Alimentaire et Sociabilité. Horizontes Antropológicos, 28 (Jul./Dez), 65-86.

Erkip, F. (2003). The shopping mall as an emergent public space in Turkey. Environment and Planning A, 35, 1073-1093.

Featherstone, M. (1991). Consumer culture \& postmodernism. Londres: Sage.

Fernandes, J. A. (2009). Retail policies and planning: the case of Portugal. Comunicação apresentada no REPLACIS Workshop de Malmoe, 10-12 de Setembro.

Firat, A. F. \& Dholakia, N. (1998). Consuming people. From political economy to theaters of consumption. Londres: Routledge.

Gardner, C. \& Sheppard, J. (1989). Consuming passion. The rise of retail culture. Londres: Unwin Hyman.

Gehl, J. \& GemzØe, I. (2004). Public spaces public life, Copenhagen. Copenhaga: Narayana Press.

Guy, C. (2007). Planning for retail development: a critical view of the British experience. Londres: Routledge.

Harvey, D. (2000). Spaces of hope. Berkeley: University of California Press.

Jayne, M. (2006). Cities and Consumption. Londres: Routledge. 
Kärrholm, M. \& Nylund, K. (2011). Escalating consumption and spatial planning: notes on the Swedish retail evolution. European Planning Studies, 19 (6), 1043-1060.

Knox, P. \& Mayer, H. (2009). Small town sustainability. Economic, social, and environmental innovation. Basel: Birkhäuser Verlag.

Lefèbvre, H. (1969). A vida quotidiana no mundo moderno. Lisboa: Editora Ulisseia.

Lichtenstein, N. (2009). The Retail Revolution: How WalMart Created a Brave New World of Business. New York, Henry Holt.

Malheiros, J., Carvalho, R. \& Mendes, L. (2013). Gentrification, residential ethnicization and the social production of fragmented space in two multiethnic neighbourhoods of Lisbon and Bilbao. Finisterra - Revista Portuguesa de Geografia, XLVIII (96), 109-135.

Massey, D. (1993). Power-geometry and a progressive sense of place. In J. Bird, B. Curtis, T. Putnam, L. Tickner (Eds.), Mapping the Futures: Local Cultures, Global Change (54-69). Londres: Routledge.

Massey, D. (1994). Space, place and gender. Cambridge: Polity Press.

Meir, A. \& Marcus, M. (1983). A commercial-blight perspective on metropolitan commercial structure. Canadian Geographer, 27 (4), 370-375.
Mendes, L. (2006). A nobilitação urbana no Bairro Alto: análise de um processo de recomposição sócio-espacial. Finisterra - Revista Portuguesa de Geografia, XLI (81), 57-82.

Mikunda, C. (2006). Brand lands, hot spots, and cool spaces: welcome to the third place and the total marketing experience. Londres: Kogan Page.

Miles, S. (2010). Spaces for consumption. Londres: Sage Publications.

Moati, P. (2011). La nouvelle révolution commerciale. Paris: Odile Jacob.

Muñoz, F. (2008). Urbanalización: paisajes comunes, lugares globales. Barcelona: Editorial Gustavo Gili.

Pirenne, H. (1969). Medieval cities. The origins and the revival of trade. Princeton: Princeton University Press.

Ravenscroft, N. (2000). The vitality and viability of town centres. Urban Studies, 37 (13), 2533-2549.

REPLACIS (2010). Retail planning for sustainable cities. In URBAN-NET (Eds.), Urban-net Research Anthology (29-34). Edimburgo: Sniffer.

Ritzer, G. (1999). Enchanting a disenchanted world: revolutionizing the means of consumption. Thousand Oaks: Pine Forge Press.

Scerri, A. \& James, P. (2009). Accounting for sustainability: combining qualitative and quantitative research in developing 'indicators' of sustainability. International Journal of Social Research Methodo$\log y, 13$ (1), 41-53.

i Projeto Urban-Net/FCT 2009-2011. Ver Barata-Salgueiro e Cachinho, 2011.

ii Town Centre Health Indicators constituem uma ferramenta metodológica de avaliação da performance dos centros urbanos, desenvolvida no Reino Unido, no quadro da Planning Policy Statement 6: Planning for Town Centres. No essencial, esta consiste num conjunto de indicadores que permitem às autarquias, em parceria com as empresas, avaliar com regularidade a vitalidade e viabilidade dos diferentes tipos de centros de comércio e serviços das cidades, e monitorizar a sua evolução, tendo em vista adequar as medidas e ações de planeamento às necessidades dos diferentes tipos de centros. 